\title{
Changes in permeability of the alveolar-capillary barrier in firefighters
}

\author{
BARBARA D MINTY,' D ROYSTON,' J G JONES,' D J SMITH,² \\ CAROLINE S M SEARING, ${ }^{2}$ AND M BEELEY*2
}

From the Division of Anaesthesia,' Clinical Research Centre, Harrow, Middlesex HA1 3UJ, and Institute of Naval Medicine, ${ }^{2}$ Alverstoke, Gosport, Hants PO12 2DL, UK

\begin{abstract}
The effect on alveolar-capillary barrier permeability of chronic exposure to a smoke produced by the partial combusion of diesel oil, paraffin, and wood was examined. An index of permeability was determined from the rate of transfer from the lung into the blood of the hydrophilic, labelled chelate ${ }^{99 \mathrm{~m}}$ Tc diethylene triamine penta-acetate (MW 492 dalton). The results of this test were expressed as the half time clearance of the tracer from the lung into the blood (T1/2LB). The study was carried out at the Royal Naval Firefighting School, HMS Excellent. Permeability index was measured on seven non-smoking naval firefighting instructors who had worked at the school for periods of longer than two and a half months. Tests of airway function and carbon monoxide transfer factor were performed on four of these seven instructors. The results of the permeability index showed a T1/2 LB of $26 \mathrm{~min} \pm 5$ (SEM) which differed significantly from that of normal non-smokers. By contrast all other lung function tests had values within the predicted normal range.
\end{abstract}

Opportunities to investigate the effect of fire smoke on pulmonary function are rare. The evidence that inhalation of smoke over a long period has a deleterious effect on pulmonary function is not conclusive. ${ }^{1-3}$ Chronic exposure to smoke increases the prevalence of respiratory symptoms and produces a change in lung volumes, but such changes are less than those observed in studies on cigarette smokers. ${ }^{45}$

Before this study, firefighting instructors at the Royal Naval Firefighting School, HMS Excellent, spent about $\mathbf{3 0 0}$ hours in smoke during a year of service; they did so while instructing naval personnel to cope with fire.

Conventional tests of pulmonary function are not particularly sensitive to the more subtle changes in lung function attributable to long term exposure to potentially harmful smokes or vapours. We have previously shown that a measurement of the permeability of the alveolar-capillary barrier to the hydrophilic chelate ${ }^{99 \mathrm{~m}} \mathrm{Tc}$ diethylene triamine penta-acetate ( ${ }^{99 m}$ TcDTPA) is a sensitive test of altered function in young symptomless cigarette

Received 5 November 1984

Accepted 26 November 1984 smokers. ${ }^{6}$ All the cigarette smokers studied had an abnormality of permeability despite the absence of evidence that they had any of the respiratory disorders recognised to be associated with chronic exposure to cigarette smoke. ${ }^{7}$

This pilot study was designed to look at the possibility that the chronic exposure to firesmoke endured by firemen might influence lung permeability. In addition, conventional tests of pulmonary function were performed. The findings resulted in a modification of the work routine of instructors who have themselves observed an increased susceptibility to respiratory tract infections while serving as firefighting instructors.

\section{Methods}

The study was carried out on firefighting instructors at the Royal Naval Firefighting School, HMS Excellent, Portsmouth. The purpose of the school is to provide naval personnel with a basic training in firefighting techniques applicable to fires on board ships. Training is given in fighting wood, diesel, and oil fires in closed buildings. Instructors are assigned to the school for about two years and are exposed to the smoke produced by wood and diesel fires two or 
three times a day for three to five days a week (about 300 hours a year). Limited protection to the respiratory tract is afforded by wearing balaclava type cotton helmets with an extension that may be raised to cover the nose and mouth. The fires were set up in large, welded metal chambers that simulated the compartments of a ship, with hatches and metal ladders down which the trainees and instructors climb during the course of an exercise. The fires are thus usually fought in a small dark enclosed space. Seven non-smoking men (age 20-34) were studied. All the subjects were fully informed as to the purpose of the study in accordance with the Helsinki declaration and gave their written consent. Conventional pulmonary function measurements were made between 1330 and 1530 and ${ }^{99 \mathrm{~m}}$ TcDTPA clearance measured on a separate day between 0830 and 1030 before the subjects' daily exposure to smoke. On three subjects ${ }^{99}$ TcDTPA clearance was repeated at the end of the working day.

\section{CONVENTIONAL PULMONARY FUNCTION \\ MEASUREMENTS}

Measurements were made of forced vital capacity (FVC) and forced expiratory volume in one second $\left(F E V_{1}\right)$, peak expiratory flow rate (PFR), and maximum mid-expiratory flow rate (MEFR). The single breath method was used to measure the carbon monoxide transfer factor which was standardised for the effective alveolar volume $\left(V_{A}\right)$ to give the transfer coefficient (KCO). The single breath nitrogen washout technique was used to obtain both closing volume, expressed as a percentage of vital capacity (CV/VC\%), and the single breath nitrogen index of distribution of ventilation (the slope between 750 and $1250 \mathrm{ml}$ of expired volume).

\section{MEASUREMENT OF RATE OF TRANSFER OF $99 \mathrm{~m}$ TcDTPA}

The permeability of the alveolar-capillary barrier was assessed by measuring the half time transfer rate of the stable chelate ${ }^{99 m}$ TcDTPA (MW 492 dalton) from the lung into the blood. The supine subjects breathed an aerosol of the tracer for three minutes. The tracer was generated from a commercial nebuliser (ACORN), the output of which was passed through a bead separator to produce an aerosol, with only $6 \%$ of particles $>2 \mu \mathrm{m}$ to ensure maximum deposition of the tracer in the alveolated regions of the lung. ${ }^{8}$

Two scintillation detectors, one positioned over the chest and the other over the thigh, measured the transfer rate of the ${ }^{99 \mathrm{~m}}$ TcDTPA from the lung to the blood and tissues. The background activity in vascular tissues within the counting field of the lung detector was subtracted as previously described.9 The index of permeability of the alveolar-capillary barrier was expressed as the time taken for the corrected activity in the lung field to fall to half its peak activity ( $T^{1} / 2 \mathrm{LB}$ mins).

\section{BLOOD SAMPLES}

Venous blood was taken from six of the instructors immediately after the end of the daily period in the chambers for estimation of carboxyhaemoglobin $(\mathrm{COHb})$ and methaemoglobin concentrations. These samples were analysed with an IL 282 cooximeter.

FIRE SMOKE ANALYSIS

The atmosphere within the chambers was sampled during both wood and diesel fires when the smoke was most dense. Dräger tubes were used for direct analysis of carbon monoxide, and the oxides of nitrogen and samples were collected into small evacuated metal canisters for subsequent analysis of oxygen and carbon dioxide by mass spectrometry.

\section{Results}

The figure shows the individual results for $\mathrm{T}^{1 / 2} \mathrm{LB}$ for the seven firefighting instructors in this study together with individual results from 55 cigarette smokers and 34 non-smokers reported elsewhere." The mean $\mathrm{T}^{1 / 2} \mathrm{LB}$ of $26 \pm 5 \mathrm{~min}$ (SEM) for the seven firefighting instructors differed significantly from the mean $\mathrm{T}^{1} / 2 \mathrm{LB}$ of $63 \pm 3.4 \mathrm{~min}(\mathrm{SEM})$ for non-smokers. The results, however, did not differ

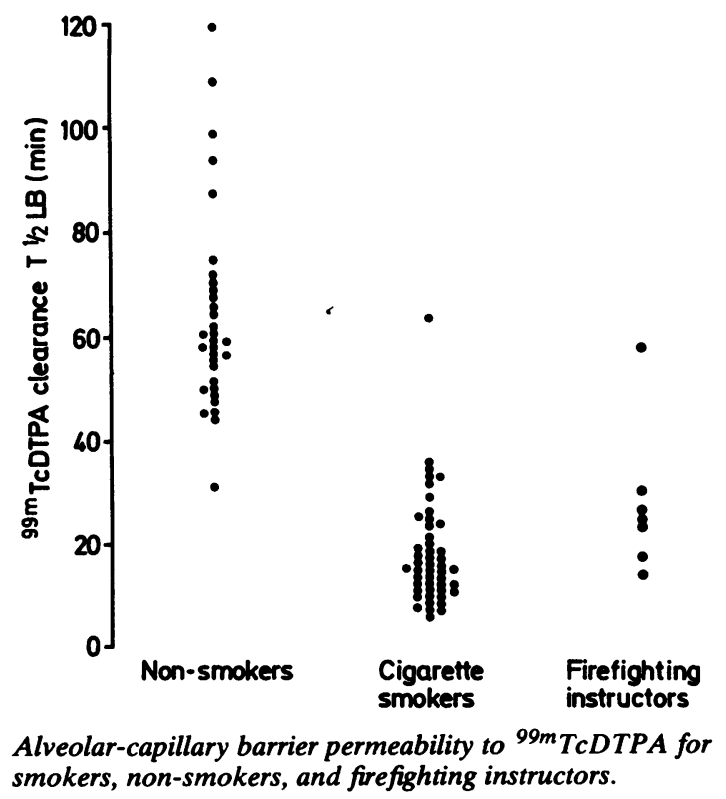
Alveolar-capillary barrier permeability to ${ }^{99 m}$ TcDTPA for
smokers, non-smokers, and firefighting instructors. 
significantly from the previously reported $\mathrm{T}^{1 / 2} \mathrm{LB}$ at $17 \pm 1.2 \mathrm{~min}(\mathrm{SEM})$ for cigarette smokers. The three instructors in whom the test was repeated at the end of a days exposure to fire smoke had no significant alteration in $T^{1} / 2$ LB. There was no correlation between the degree of abnormality and the length of time the subjects had worked at the firefighting school.

The table shows the concentrations of carbon monoxide and oxides of nitrogen measured in the chambers and the oxygen and carbon dioxide concentrations measured at the same times.

All results of conventional lung function fell within the limits of predicted values. Mean values for carboxyhaemoglobin $0.9 \pm 0.1 \%$ (SEM) and methaemoglobin $0 \cdot 6 \pm 0 \cdot 2 \%$ (SEM) were not raised above those of normal controls.

\section{Discussion}

This study has shown that chronic exposure to fire smoke caused changes in the permeability of the alveolar-capillary barrier to ${ }^{99 \mathrm{~m}} \mathrm{TcDTPA}$ in nonsmokers. These changes are similar in magnitude to those previously shown in cigarette smokers. ${ }^{9}$ By contrast we were unable to shown any decrement in conventional tests of lung function. In this study we have compared the results of a small group of firefighting instructors with large groups of cigarette smokers and non-smokers studied in the past. This statistical comparison is justified because (1) the mean transfer rate of ${ }^{99 \mathrm{~m} T c D T P A}$ for different groups of smokers has not changed significantly during the three years in which we have been performing this test ${ }^{61011}$ and (2) the transfer rate of the tracer is not correlated with age or body size and there is no significant difference between sexes (unpublished observations).

The effect on the lung of inhaling either cigarette or fire smoke may be caused either by direct action on the pulmonary epithelium or through stimulation of cells such as alveolar macrophages. The identity and mode of action of the harmful constituents of cigarette or fire smoke is not known with complete certainty. Both types of smoke are complex mixtures of particulate matter and gases. Many of the gases,

Chamber concentrations of oxygen, carbon dioxide, carbon monoxide, and oxides of nitrogen during wood and diesel fires

\begin{tabular}{lcc}
\hline & Wood fure & Diesel fure \\
\hline Oxygen (\%) & $16 \cdot 2$ & $17 \cdot 0$ \\
Carbon dioxide (\%) & $1 \cdot 2$ & $0 \cdot 8$ \\
Oxides of nitrogen (ppm) & 0 & 2 \\
Carbón monoxide (ppm) & 850 & 100 \\
\hline
\end{tabular}

in particular carbon monoxide, acrolein, oxides of nitrogen, and hydrogen cyanide, are common to both fire and cigarette smoke. Technical limitations due to the isolated position of the exposure chambers in this study prohibited a detailed examination of the composition of the fire smoke. Although there was only a negligible quantity of the oxides of nitrogen in the smokes from either the wood or diesel fires, there was a significant amount of carbon monoxide, particularly in the wood fire smoke. We have recently shown a significant correlation between carboxyhaemoglobin concentration and alveolar barrier permeability in cigarette smokers. ${ }^{12}$ This association, however, does not necessarily imply that carbon monoxide was the causative agent but only that the degree of alteration in permeability was proportional to the amount of cigarette smoke inhaled. Although the carbon monoxide levels in the wood fire smoke were high, the short exposure time of the instructors (about five minutes) was unlikely to raise the carboxyhaemoglobin levels significantly. ${ }^{13}$ No instructor exposed to smoke had a $\mathrm{COHb}$ of more than $1.3 \%$, and the mean value for $\mathrm{COHb}$ was similar to that found in non-exposed subjects. Similarly methaemoglobin, used as an index of exposure to the oxides of nitrogen, was not raised. These data may provide supporting evidence that carbon monoxide is not the cause of the abnormal permeability seen either in the firefighting instructors or in cigarette smokers.

A deleterious effect on the pulmonary epithelium may be mediated by alveolar macrophages because the increased lung burden of particles inhaled from the smoke is known to stimuate the recruitment into the airways of phagocytic cells, particularly alveolar macrophages and polymorphonuclear neutrophils. ${ }^{14}$ Toxic products of these cells occupy a central role in current views concerning the pathogenesis of lung injury induced by cigarette smoke, and chronic inhalation of fire smoke would probably affect the lung by similar mechanisms. One of the potentially toxic products of phagocytic cells are proteolytic enzymes, and the altered balance of protease-antiprotease in the lower airways is a widely held explanation for the development of emphysema. ${ }^{15}$ Another possible mechanism of injury to the alveolar-capillary barrier is damage resulting from oxidants. There is substantial evidence that reactive oxygen intermediates may damage many cell components. ${ }^{16}$ These may either be inhaled or released from lung phagocytes. Toxic oxidant species are present in cigarette smoke in concentrations of $2 \times 10^{15}$ free radicals per puff ${ }^{17}$ and are likely to be in similar concentrations in fire smoke. The other potential source of oxidants are the lung phagocytes that release several reduced oxygen species including superoxide anion, hyd- 
rogen peroxide, and hydroxyl radical. ${ }^{18}$ This production of oxidant is greatly increased after stimulation with particulate matter. ${ }^{19}$

The instructors examined in this study had relatively short exposures to smoke and the results of the conventional lung function tests were within the predicted normal range. The only detectable abnormality in pulmonary function was the increase in permeability of the alveolar-capillary barrier. Nevertheless, a greater deterioration of pulmonary function with age has been shown in firefighters than in non-firefighters. ${ }^{4}$ The degree of abnormal permeability shown in our study is a process that by itself causes no clinically demonstrable pulmonary disability. It probably, however, represents the effect of an alteration in lung phagocyte population which may enhance susceptibility to enzymatic attack caused by bacterial and viral infections or by inhalation of dust. The alterations in permeability may facilitate the egress of proteolytic enzymes into the interstitium and lead to the development of emphysema. ${ }^{20}$ Both civilian and service firefighters have relatively short lifetime exposure to smoke compared with cigarette smokers, and this may explain the greater tendency for smokers to develop chronic obstructive airways disease.

Finally, we would suggest that further investigations to identify more clearly which of the constituents of the firesmoke are particularly damaging to the lung should have a practical application in the design of better breathing apparatus for firefighters and pinpoint whether they should concentrate on filtering the particulate matter or whether it is more important to attempt to remove specific gases from the inhaled smoke.

We thank Lt Cdr A Jackson RN and his staff at HMS Excellent for their willing cooperation and tolerance during the study at the Royal Naval Firefighting School.

\section{References}

' Unger KM, Snow MR, Mestos JM, Miller WC. Smoke inhalation in firemen. Thorax 1980;35:838-42.
${ }^{2}$ Young I, Jackson J, West S. Chronic respiratory disease and respiratory function in a group of fire fighters. Med $J$ Aust 1980;1:654-8.

${ }^{3}$ Sparrow D, Bosse R, Rosner B, Weiss ST. The effect of occupational exposure on pulmonary function. A longitudinal evaluation of firefighters and non-firefighters. Am Rev Respir Dis 1982;125:319-22.

${ }^{4}$ Higgins ITT. Epidemiology of chronic respiratory disease: a literature review. Washington, DC: US Environmental Protection Agency, Office of Research \& Development, 1974:1-129.

${ }^{5}$ Ashley F, Kannel WB, Sorlie PD, Masson R. Pulmonary function: relations to aging, cigarette habit, and mortality. The Framingham study. Ann Intern Med 1975;82:739-45.

- Minty BD, Jordan C, Jones JG. Rapid improvement in abnormal pulmonary epithelial permeability after stopping cigarettes. $\mathrm{Br}$ Med J 1981;282:83-6.

' US Public Health Service Smoking \& Health: Report of the Surgeon General. Washington, DC: US Government Printing Office, 1979. (DHEW publication No (PHS) 79-50066.)

${ }^{8}$ Royston D, Minty BD. A cheap simple particle generator system for use with in vivo measurement of alveolar-capillary barrier permeability. Am Rev Respir Dis 1983;127:319.

- Jones JG, Royston D, Minty BD. Changes in alveolar capillary barrier function in animals and humans. Am Rev Respir Dis 1983; 127:S51-9.

'" Jones JG, Minty BD, Lawler P, Hulands G, Crawley JCW, Veall $\mathrm{N}$. Increased alveolar epithelial permeability in cigarette smokers. Lancet 1980; i:66-8.

" Minty BD, Royston D, Jones JG. Relationship between pulmonary epithelial permeability and HbCO. Thorax 1982;37:709.

12 Jones JG, Minty BD, Royston D, Royston JP. Carboxyhaemoglobin and pulmonary epithelial permeability in man. Thorax 1983;38:129-33.

13 Coburn RF, Forster RE, Kane PB. Considerations of the physiological variables that determine the blood carboxy- $\delta$ haemoglobin concentration in man. $J$ Clin Inves $\bar{c}$ 1965;44:1899-1910.

14 Hunninghake GW, Crystal RG. Cigarette smoking and lung des truction. Accumulation of neutrophils in the lungs of cigarettesmokers. Am Rev Respir Dis 1983;128:833-8.

is Hoidal JR, Niewoehner DE. Pathogenesis of emphysema. Chest 1983;83:679-85.

${ }^{10}$ Fridovich I. The biology of oxygen radicals. Science 1978;201:875-80.

17 Pryor WA. Methods for detecting free radical and free radical mediated pathology in environmental toxicology. In: Bhatnager RS, ed. Molecular basis of environmental toxicity. Ann Arbor: Ann Arbor Science Publishers, 1980.

${ }^{18}$ Hoidal JR, Beall GD, Repine JE. Production of hydroxyl radical by human alveolar macrophages. Infect Immun 1979; 26:1088-94.

${ }^{19}$ Hatch GE, Spock A, Gardner DE, Menzel DB. Differences between particulate and peptide stimuli on activation of oxidant production in alveolar macrophages. Chest 1980;2:267-9.

${ }^{20} \mathrm{Hogg}$ JC. The effect of smoking on airway permeability. Chest 1983;83:1-2. 